Journal of Contemporary Educational Research

Research Article

\title{
Research on Cloud Platform Teaching Mode-Take Literary Psychology as an example
}

Baoxun Wang

Heilongjiang Preschool Education College, China

Funding: Project title of the special project of 2020 Education Science Planning; Research on the Strategy of Using Cloud Platform Literature Courses to Carry Out Online Teaching Under Covid-19 Epidemic Situation.

\begin{abstract}
With the rapid development of information technology, the impact of the internet on education reformation is growing. Various courses in colleges and universities have gradually applied the combination of internet platform and course teaching to explain knowledge for students. In this context, literary psychology should also introduce information technology, and keep pace with the times, actively carry out practical teaching.
\end{abstract}

Key words: Cloud platform; Teaching mode; Literary psychology

Publication date: October, 2020

Publication online: 31 October, 2020

*Corresponding author: Baoxun Wang,7412018@ qq.com

\section{Introduction}

The study of literary psychology has been suspended for half a century in China, but it was suddenly mentioned and developed rapidly in the 1980s, which is a new trend in the literary and artistic circles in the new era. Currently, whether in literary creation or literary criticism, the study of literary psychology has become a very attractive subject in academic circles. On the platform of local universities, dozens of universities offer "literary psychology" courses in different ways. With the rapid development of information technology, new information technologies such as Web2.0, cloud computing and network are emerging. Internet, mobile reading, micro blog and other media, the education function of the Internet is constantly upgrading. The modern media technology represented by tablet, smart phones and e-books is also constantly applied in the field of education, the internet becoming extremely important in the field of education. The reformation and development of information technology getting more and more influence to break the boundaries between space-time in all kind of industries, teachers and students able to utilize a lot of useful information to provide education in anytime and anywhere. The role of teachers and students is changing, and the dual transformation of teaching and learning is being vigorously promoted by all parties ${ }^{[1][2]}$.

\section{The significance of teaching application based on Tencent classroom and smart teaching cloud platform}

Through the application of comprehensive teaching activities based on Tencent classroom and intelligent lecture cloud platform, we can directly observe the changes of students in learning.

\subsection{Promote effective classroom teaching}

\subsubsection{Can effectively activate the classroom teaching atmosphere}

With the popularity of Tencent classroom and intelligent education cloud platform, teachers and students can interact in the course. Meanwhile, students can use more space and information to express themselves freely on a broad platform without obstacles. It is difficult for introverted students to express themselves in the normal teaching process. However, they can now fully display their talents on the platform, teachers can also explore 
the bright points of different levels students.

\subsubsection{Hierarchical teaching}

In the comprehensive teaching design activities, Tencent classroom and intelligent education cloud platform learning platform provide the possibility of hierarchical education. Tencent classroom and intelligent education cloud platform automatically analyzes the whole class situation according to students learning, activities and test conditions, fully analyze students' problems, teachers can then carry out reasonable hierarchical education based on this analysis. The arrangement can fully reflect the students' learning, activities, examinations and other contents to meet the actual needs of students. Each person can carry on the appropriate time activity according to his own ability. Improve students' confidence in literature learning ${ }^{[3]}$.

\subsubsection{Regulating teaching process}

Tencent classroom and intelligent education cloud platform are suitable for various types of schools, courses, disciplines and lectures. In the traditional classroom teaching, the classroom rules are limited because teachers must complete the teaching tasks under the premise of maintaining order. Students were divided into several different learning areas because teachers have to pay attention to the different performance of students in class. In the cloud platform teaching, other than proposing the target goal, teachers can also let students have enough time for free discussion and provide personal guidance. Under this relax atmosphere, students will not feel helpless, meanwhile, they are not absolutely free because they also have clear task orientation. Since all students are carrying out various activities in Tencent classroom and intelligent speech cloud platform, they can supervise each other and form effective and positive constraints.

\subsubsection{Effectively changing the traditional roles of teachers and students}

The comprehensive practice activities based on Tencent classroom and smart teaching cloud platform can fundamentally change the traditional roles of teachers and students in the classroom. The practice let students playing as main part, having equal status on the platform, teachers and students can communicate openly without any objection in friendly atmosphere. It had fully mobilizes the interaction between teachers and students and the mutual collaboration between students. Students become constructors in activities, and teachers become real guider.

\subsection{Promoting students' growth}

The comprehensive practice of literary psychology is to enable students to enrich their emotions, attitudes and values, and acquire knowledge and skills through various activities and flexible learning methods. This is a generative course. It is in the process of interweaving and interacting among these factors that students realize the formation and improvement of their own quality.

\subsection{Promoting teachers' professional development}

China's comprehensive practical activities based on Tencent classroom and intelligent education cloud platform bring new challenges and experiences to teachers' educational behavior. Categorizing before class, classroom teaching and reviewing after class have changed the traditional teaching mode. Practicality and openness bring more space for teachers' professional development.

\subsubsection{Changing the teachers' concept}

The traditional literature course is based on learning and pays attention to the systematization of knowledge, and its learning method is mainly based on reception learning. The most comprehensive Chinese practice activities are based on a specific project or topic. It focuses on training student's ability to discover, analyze and solve problems. During the process of activities, we should pay attention to the training students inquiry ability and cooperative spirit, and carry out practical and experiential learning. This enables teachers to think and adjust their educational concepts and behaviors.

\subsubsection{Improve teaching ability}

There are many textbooks that can be quoted in Chinese comprehensive practice activities, but there are no ready textbooks to realize Chinese comprehensive practice activities based on Tencent classroom and intelligent teaching cloud platform. Therefore teachers cannot only rely on textbooks, but also need to expand the scope of text learning, enter students' life, go deep into the platform, enter the students' spiritual world, and explore interesting and meaningful activity themes which suitable for students. With the improvement of teachers' ability to develop curriculum, teachers are encouraged to "regulate and control online and offline activities" and "how to effectively configure students to implement platform-based activities".

\subsubsection{Adjust teachers' emotion}


Due to the content of lectures is fixed, teachers' personality and psychological characteristics easy to be covered up. Therefore, lectures become mechanical and repetitive, which seriously limits teachers' creativity and resulting tiredness in lecture. It is a great achievement for teachers to design and implement traditional knowledge in the comprehensive practice of literature and transform it into various practical activities.

\subsection{Theoretical basis of Tencent classroom and smart teaching cloud platform application}

Multiple intelligences theory, "lifelong education" theory and constructivism learning theory had strongly supported the application of literature comprehensive practice activities based on Tencent classroom and smart education cloud platform.

\subsubsection{Theory of Multiple Intelligences}

The founder for the theory of multiple intelligences is Howard Gardner, a professor of developmental psychology at Harvard University. It is believed that Human intelligence includes speech intelligence, logic and mathematics intelligence, visual spatial relationship intelligence, music rhythm intelligence, body movement intelligence, interpersonal intelligence, self-reflection intelligence, natural observer intelligence, presence intelligence and so on. Gardner's theory of multiple intelligences has a significant impact on the application of comprehensive teaching practice in China ${ }^{[4]}$.

\subsubsection{Life education theory}

According to the actual situation of Chinese education, focusing on the global education situation, and based on Dewey's criticism of "education is life", Tao Xingzhi constructed the theoretical system of "life education". The basic contents are "life is education", "society is school" and "combination of teaching and practice". This is not only Tao Xingzhi's great contribution to Chinese education, but also the beginning of future education. Life is education, which is the core of Tao Xingzhi's life education theory ${ }^{[5]}$.

\subsubsection{Constructivist learning theory}

Constructivism is the theory of knowledge and learning. The core of the theory is to emphasize the initiative of learners, pay attention to students, emphasize the active exploration, discovery of knowledge and the active construction of knowledge meaning. The innovation of constructivism theory holds that students are active constructors of meaning. It clarifies the main purpose of education, emphasizes the subjective state of students, focuses on combining students' own experience, and determines the meaning of knowledge in dialogue, communication and questioning. ${ }^{[6]}$

\section{Application strategy of literary psychology in cloud platform teaching}

\subsection{Take students as the foundation and prepare lessons carefully}

The preparation for class is the basis of a good class. Especially, the main contents of course preparation should include knowledge point preparation, student preparation and course preparation.

\subsubsection{Prepare knowledge points}

First of all, we must ensure the accuracy, scientificity and strictness of knowledge points. The explanation of knowledge points needs the help of case analysis. When describing each knowledge point as the theoretical process of literature and art, we often choose two examples, one is the classic text example, another one is based on the real life as example. New phenomena in literature and art as well as students' interests will be changed in time according to the students' situation. For example, in order to illustrate the knowledge point of "the contradictory unity of form and content", several examples can be replaced, such as the viscount in two, all the nights in the world, and the fantasy drifting of the youth school. We can choose appropriate examples according to the hot spots of the times, use these examples to stimulate students' interest, and then use the theory in the textbook to analyze new phenomena in literature and art.

\subsubsection{Prepare students}

The so-called prepare students mainly refers to have a full understanding to the students' knowledge structure, interest and acceptance psychology. Take the teaching of "literary psychology" as an example. In terms of knowledge storage, this course is a professional elective course for a series of literature and art courses. It is usually offered to junior students majoring in literature. The students have studied the professional courses such as introduction to literature, introduction to literary criticism, introduction to aesthetics, etc., they have the experience of reading specific texts and have special basic knowledge. Therefore, "art psychology" course is mainly from the perspective of "psychology". In order to guide students to conduct more in-depth literature 
and art research, it is important to introduce theoretical vision and cultivate research ideas, rather than text interpretation.

\subsubsection{Prepare for class}

This mainly refers to the process of pre-setting the whole classroom teaching. There may be various emergencies occur in the classroom, but proper preparation is needed if the situation can be predicted. For example, how do students respond to the explanation of specific knowledge points? What is the expected effect of setting up interactive links? If my students are actively involved, how should I guide them? What if students don't have motivation? Along with the continue of this situation, with the gaining of teachers' teaching experience, teachers will become more mature for understanding in the overall situation of the curriculum.

\subsection{Using new technology to shape new classroom}

"The media will change all the lifestyles they come into contact with," McLuhan said. In internet plus era, the biggest impact of university education is the rapid expansion of the internet, and the students are no longer confined to ivory towers. Therefore, college classroom teaching must be facing the following problems:

(1) In the new media era, users mainly use fragmentation time to obtain information. What really works is fragmented, thematic and repetitive hot information. A lot of humanistic information is locked in the microcomputer. The information that students receive on the internet is numerous. The information that students get on the internet is far beyond their ability to digest, absorb and understand. Compare with the convenience that media had brings to students, teachers need to pay more attention to the guidance methods for letting students improve their ability to filter information.

When allowing students to enjoy the freedom and convenience brought by the online world, due to the development of media technology that makes use of internet for knowledge learning, teachers should also see "the contradictory combination of technology and humanities".

According to the dissemination characteristics of the network, people is constantly inculcated on the network for learning. In the long run, it is difficult to carry out in-depth and in-depth research and thinking. Should we urge students to get rid of this subdivision learning method? Or is it based on the in-depth study of the thinking nature of decentralized learning to take advantage of this situation and play its unique role? Or do they complement each other through intensive learning and short-term learning? In facing of these challenges, university teachers must take their own professional education as the basis, seriously consider and deeply study.

The breadth of network knowledge and the convenience of information brought new challenges to the transfer of professional knowledge. Students can obtain video lectures of top teachers from various professional fields on the Internet. University teachers should facing the rapid development of new media technology and its changes, make full use of the convenience brought by the development of the internet, and update their teaching ideas and teaching methods.

\subsection{Build the concept of "lifelong learning"}

Habermas said: "human beings are maintained through the social coordination of their members, which must be achieved through communication. From the "peopleoriented" education concept, the author is in the normal classroom. In education, we try to change the traditional "subject object" mode of teacher-student education and create an equal, harmonious and coexisting educational atmosphere of "communication and dialogue" between teachers and students. First of all, we should trust students, fully understand their learning motivation, interest and their current knowledge level, treat students in the same way, and teach them according to their own talents, and use unified standards to measure students. Secondly, in the process of getting along with students, teachers must realize and perform their duties. For example, when reaching a learning consensus with students, it is necessary to establish strict learning standards, and develop good learning habits and a sense of responsibility to students. It also guides students to constantly surpass themselves and gradually change their knowledge concept. It also guides students to fail and accept different levels of feedback to adapt to different levels of students. Create a safe learning environment for students and then try to stimulate their curiosity.

\section{Conclusion}

Cloud platform teaching (WebQuest) is mainly carried out through the internet. In many modules, the configuration of resource module is especially 
important. The current network resources faced by students are very complex, when setting up resources for students, teachers must fully consider the characteristics of students, and ensure that they can fully utilize network resources, rather than wasting time. In the process of homework, teachers can use resources to intervene students' behavior to ensure the progress of research and achieve creative achievement at the end.

\section{References}

[1] Lan XM. Analysis on Teaching Strategies of literary psychology [J]. Guangxi Education, 2018 (19): 114-115.

[2] Li Y. Transformation ideas of literature and art teaching in the
Internet era $[\mathrm{J}]$. Teaching and educating people (Higher Education Forum), 2017 (21): 110-112.

[3] Sun H. Integrating teaching resources to cultivate innovation ability -- Research on the innovation of teaching mode of literature and Art Curriculum Group [J]. Theoretical observation, 2015 (10): 11-13.

[4] Liu XX, Wang F. Theory of multiple intelligences and class management $[\mathrm{J}]$. Science and education guide (next xunjian), 2020 (07): 171-172 + 184.

[5] Jiang CF, Li H, Zhang SJ. Research on the application of inquiry teaching in flipped classroom from the perspective of constructivism theory $[\mathrm{J}]$. Journal of science and education, 2020(8): 31-33.

[6] Zheng FA, Sun HY. The Enlightenment of Tao Xingzhi's life education theory on ESP teaching in Applied Universities [J]. Northern Literature, 2019(30): 175. 